PROFESIONALES Y HERRAMIENTAS PARA EL DESARROLLO LOCAL Y SUS SINERGIAS TERRITORIALES. EVALUACIÓN Y PROPUESTAS DE FUTURO IX Coloquio Nacional de Desarrollo Local del GTDL-AGE 

ANTONIO MARTÍNEZ PUCHE, XAVIER AMAT MONTESINOS, ISABEL SANCHO CARBONELL y DANIEL SANCHIZ CASTAÑO (EDS.)

\section{PROFESIONALES Y HERRAMIENTAS PARA EL DESARROLLO LOCAL Y SUS SINERGIAS TERRITORIALES. EVALUACIÓN Y PROPUESTAS DE FUTURO}

IX Coloquio Nacional de Desarrollo Local del GTDL-AGE

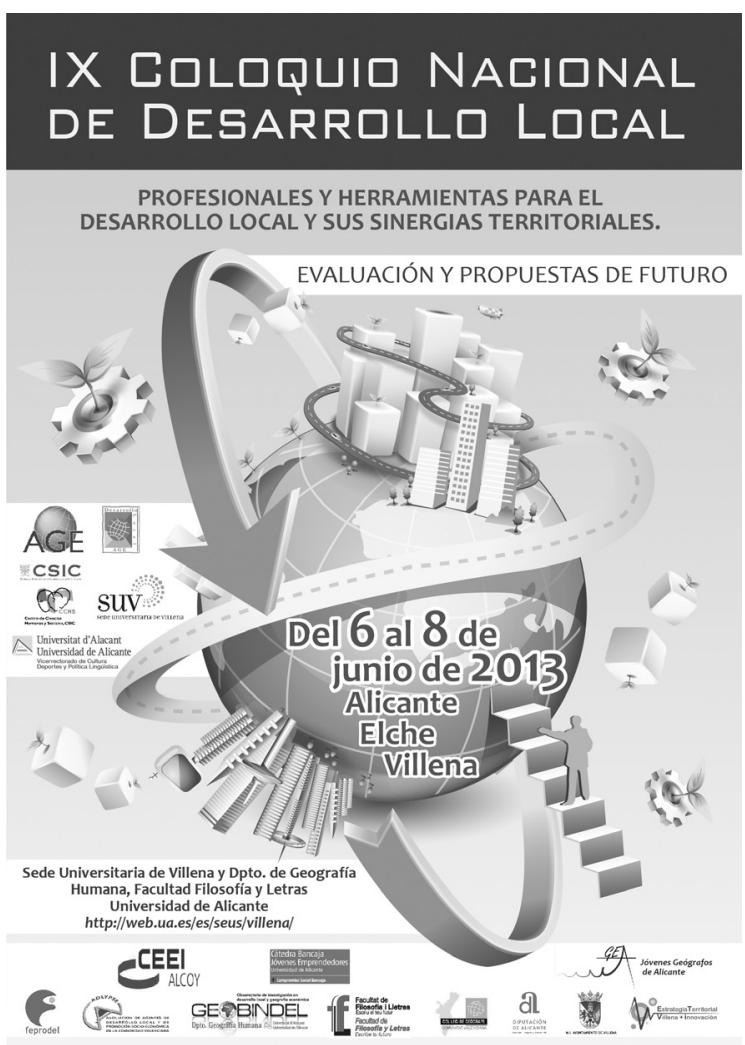


Este libro ha sido examinado y valorado por evaluadores ajenos a la Universidad de Alicante, con el fin de garantizar la calidad científica del mismo.

Publicacions de la Universitat d'Alacant

03690 Sant Vicent del Raspeig

Publicaciones@ua.es

http://publicaciones.ua.es

Telèfon: 965903480

(C) Antonio Martínez Puche, Xavier Amat Montesinos,

Isabel Sancho Carbonell y Daniel Sanchiz Castaño (eds.), 2016

(C) d'aquesta edició: Universitat d'Alacant

ISBN: 978-84-16724-00-0

Dipòsit legal: A 92-2016

Disseny de coberta: candela ink

Composició: Página Maestra (Miguel Ángel Sánchez Hernández)

Impressió i enquadernació: Guada Impresores

\section{unte \\ Unión de Editoriales
Universitarias Españolas \\ WWW.une.es
WWA}

Esta editorial es miembro de la UNE, cosa que garantiza la difusión y comercialización nacional y internacional de sus publicaciones.

Reservados todos los derechos. Cualquier forma de reproducción, distribución, comunicación pública o transformación de esta obra sólo puede ser realizada con la autorización de sus titulares, salvo excepción prevista por la ley. Diríjase a CEDRO (Centro Español de Derechos Repográficos, www.cedro.org) si necesita fotocopias o escanear algún fragmento de esta obra. 


\title{
LA POTENCIACIÓN DEL ESPACIO RURAL COMO MOTOR DE DESARROLLO LOCAL, ANTE LA ACTUAL CRISIS INDUSTRIAL EN LA COMARCA DEL ALTIPLANO (MURCIA)
}

\author{
Francisco José Morales Yago \\ Universidad Nacional de Educación a Distancia \\ fjmorales@geo.uned.es
}

\section{RESUMEN}

La comarca del Altiplano de Murcia formada por los municipios de Jumilla y Yecla sufre una grave crisis en su modelo industrial actual. La falta de competitividad ante el empuje de otros espacios emergentes exige un cambio estratégico. Surge la necesidad de potenciar el espacio rural no solamente como soporte de la tradicional actividad basada en la agricultura y ganadería, también y aquí está la novedad en la aparición de usos terciarios, para ello se proponen como líneas de activación económica una serie de actuaciones, las cuales ayudarán en la búsqueda de soluciones ante la falta de alternativas actuales.

Palabras clave: desarrollo local, agricultura, enoturismo, paisaje, Altiplano de Murcia.

\section{EMPOWERMENT OF RURAL AREA DEVELOPMENT AS LOCAL MOTOR BEFORE THE CURRENT INDUSTRIAL CRISIS IN THE REGION OF THE HIGHLANDS (MURCIA)}

\section{ABSTRACT}

The Altiplano region of Murcia formed by the towns of Jumilla and Yecla suffers a serious crisis in its current industrial model. The inability to compete with the thrust of other emerging areas requires a strategic shift. Arises the need to strengthen rural areas not only in support of the traditional activity based on agriculture and livestock, and also here is the new addition to the appearance of tertiary uses for this are proposed as economic activation lines a 
series of actions, which will help in the search for solutions to the current lack of alternatives.

Key words: local development, agriculture, wine, landscape, Altiplano de Murcia.

\section{INTRODUCCIÓN}

Tradicionalmente la comarca del altiplano murciano había basado su economía en la actividad agraria, este hecho produjo en este espacio una economía generadora de rentas bajas, de lenta acumulación de capitales y por consiguiente de una economía débil, de escaso desarrollo y proyección exterior. En la década de los 60, muy en sintonía con el arranque del proceso industrial en España, debido en gran parte a los planes de estabilización a partir de 1959, en la comarca comenzaron a transformarse el ritmo de las actividades existentes y por otro lado se iniciaron otras nuevas, sobre todo en el sector industrial.

En una ambiente generalizado por la economía agraria, se observa la existencia de un espacio de tradición histórica en la manufactura de artesanías en madera (toneles, sillas, etc); esta tradición junto a otras serie de circunstancias como la influencia clara de la vecina comunidad valenciana, el espíritu de riesgo de los empresarios, la imaginación en el diseño y creación de pequeñas redes comerciales fueron la célula de una realidad concreta: la dinamización del sector del mueble e industrias afines. La llegada de la prosperidad económica supuso la detención de las migraciones, una convulsiva renovación urbana y el aumento de bienestar social hasta cotas difícilmente imaginables en aquellos años de incertidumbres anunciadas.

\section{El VALOR DINAMIZADOR DE LA ACTIVIDAD AGRARIA}

La actividad agraria en la comarca ha sufrido una gran transformación en varios aspectos: volumen de productividad, técnicas de cultivo, adaptación de nuevos cultivos que han sustituido a los tradicionales, etc; todo ello evidentemente se enmarca en un espacio físico distinto, nuevo parcelario, aparición tímida de actividades terciarias como el turismo rural, que se basaría en la aparición de alojamientos y enoturismo (ALONSO, 2003). La llegada de la globalización también supuso una apertura de mercados, el desarrollo del transporte y venta de productos alimentarios que han crecido enormemente, la posibilidad de llevar víveres a cualquier parte del mundo en un tiempo record, fue un aspecto que hizo entrar a la actividad agraria en el mundo de la competitividad.

El denominado "éxodo rural" provocó el abandono progresivo del campo para vivir en la ciudad. En la actualidad el uso cotidiano del automóvil ha sido definitivo en las preferencias de los agricultores que han optado por vivir en la ciudad y desplazarse diariamente a su lugar de trabajo: el campo. La organiza- 
ción de la economía en estas últimas décadas determinó que la agricultura tradicional fuese reemplazada por la denominada "agricultura de mercado" o "comercial". Y este hecho ha quedado reflejado en el paisaje de forma profunda. Por ejemplo, aparecieron infraestructuras de regadío como los embalses para conservar el agua, sistemas de goteo o aspersión, o también la consolidación de nuevas vías de comunicación bien organizadas, así como otras cuestiones de cambios en el trazado parcelario, el tipo de hábitat, etc.

Las explotaciones se modernizaron introduciendo nuevas técnicas de producción y gestión. Las pequeñas propiedades se asociaron en cooperativas que proporcionaron al agricultor no sólo ayuda en la producción y en la comercialización, sino también asesoría técnica y defensa de sus derechos. La actividad agrícola y ganadera se encontró cada vez más vinculada a la industria agroalimentaria. Gracias a los transportes modernos, a los avances en la gestión comercial y al gran nivel profesional de los agricultores se aceleró el proceso de especialización agraria de tal manera que cada región produjera aquello para lo que estaba mejor dotada. El ejemplo en la Región de Murcia ha sido palpable, la producción de frutas dio lugar a una importante industria exportadora de mermeladas y todo tipo de conservas vegetales enlatadas y zumos.

En esta situación de cambios relevantes aparecieron nuevas actividades surgidas en el medio rural y que en la mayoría de los casos son casi siempre el resultado de la influencia urbana: segundas residencias, naves industriales para actividad agroindustrial, reservas de agua y áreas de caza, en algunas ocasiones poco respetuosas con el equilibrio biológico. El desarrollo rural trata hoy de impulsar actividades complementarias, como el turismo rural y la actividad artesanal y asigna al campo la tarea de salvaguardar los recursos y el patrimonio natural, conservando y protegiendo el suelo fértil, los paisajes, los bosques y las riquezas ecológicas. De esta manera el mundo rural deja de ser un espacio exclusivamente agrario para convertirse en un espacio más diversificado.

Los cambios en la actividad agropecuaria se reflejan en la agricultura tradicional, que ha quedado desplazada por una tendencia comercial exportadora, especializada en cultivos rentables y competitivos. También se abandonaron las antiguas tendencias al autoconsumo que requerían un policultivo con efectos incluso de trueque entre los mismos agricultores. Los cambios experimentados han dejando una gran huella en el paisaje agrario; hemos asistido a la transformación de los sistemas de cultivos y al cambio de los mismos como la implantación de sistemas de regadíos que abandonaron el sistema tradicional, mucho más despilfarrador en consumo de agua, pasando por ejemplo de "riegos a manta" a goteo o aspersión. También la reordenación y mejora de caminos rurales, el abandono de las tierras menos productivas y la integración en la U.E. han sido determinantes en una agricultura que ha pasado muchas veces por la posibilidad de alcanzar subvenciones. 
3. EL VINO, PRIMER ELEMENTO DE INTERNACIONALIZACIÓN DE LA ECONOMÍA LOCAL AGRARIA

El cultivo más importante de la comarca es el viñedo y la producción de vino ha desarrollado la exportación de los caldos a diversas partes del mundo. De hecho en certámenes vinícolas no faltan los vinos de la comarca. Y esta circunstancia hace también que la producción vinícola generalmente consumida en territorio nacional haya acaparado mercados internacionales.

El cultivo de la vid se debió introducir en la comarca en época romana. A pesar de la prohibición existente con el fin de proteger la exportación existente de los vinos procedentes de la península italiana, en el Bajo Imperio aparece la vid por toda la Baética y Carthaginense; así lo atestiguan los restos de ánforas, de un tipo especial destinado a la exportación del vino, hallados en el cabezo del Tío Pío de Archena (BELDA, 1970).

A partir de 1905 la crisis vitivinícola no sólo se debió al bajo precio del vino, sino a los efectos de los ataques de la filoxera en esta zona, sobre todo en aquellas plantaciones que se habían hecho sobre suelos arcillosos, por lo que muchos agricultores procedieron a su arranque.

Es desde 1950 cuando la viticultura va a experimentar su mayor expansión dentro de la comarca, una evolución frenada tal como señalábamos a partir de 1986 con la entrada de España en la Unión Europea. Tras la reestructuración del viñedo, las ayudas al arranque y puesta en funcionamiento de las tierras más aptas para el cultivo, a partir de la década de los noventa se observa una ligera recuperación que alcanza de nuevo los datos de los años 50. Veamos lo más relevantes en la actualidad:

Cuadro $n^{o} 1$ Evolución superficie total de las explotaciones agrarias en la Región de Murcia, Jumilla y Yecla

\begin{tabular}{|c|c|c|c|c|c|c|}
\hline & \multicolumn{2}{|c|}{ Región de Murcia } & \multicolumn{2}{c|}{$\begin{array}{c}\text { Término municipal de } \\
\text { Jumilla }\end{array}$} & \multicolumn{2}{c|}{$\begin{array}{c}\text { Término municipal de } \\
\text { Yecla }\end{array}$} \\
\hline & Secano & Regadío & Secano & Regadío & Secano & Regadío \\
\hline 2004 & 33005 & 14078 & 17578 & 3336 & 8405 & 5605 \\
$\%$ & 2,91 & 1,24 & 18,14 & 3,44 & 13,87 & 9,25 \\
\hline 2005 & 32549 & 14834 & 17461 & 3336 & 8405 & 5635 \\
$\%$ & 2,87 & 1,31 & 18,01 & 3,44 & 13,87 & 9,30 \\
\hline 2006 & 32143 & 14561 & 17461 & 3336 & 8405 & 5635 \\
$\%$ & 2,84 & 1,28 & 18,01 & 3,44 & 13,87 & 9,30 \\
\hline 2007 & 31243 & 14595 & 16810 & 3336 & 7764 & 5635 \\
$\%$ & 2,84 & 1,28 & 17,34 & 3,44 & 12,81 & 9,30 \\
\hline 2008 & 30727 & 14112 & 16630 & 3181 & 7584 & 5431 \\
$\%$ & 2,71 & 1,24 & 17,16 & 3,28 & 12,52 & 8,96 \\
\hline
\end{tabular}

Fuente: Anuario Estadístico de la Región de Murcia. 
Aunque los datos que conocemos son muy recientes, observamos cómo la aparición del regadío ha incidido en el progresivo cambio de muchas tierras, que aumentan la productividad de forma importante. Incluso se liberan tierras dedicadas a cultivos tradicionales de secano (cereales) a otros cultivos de temporada como: lechugas, melón, alcachofa, pimiento o bróculi.

En cuanto a la exportación de los vinos de la ciudad, los principales países importadores pertenecen a la U.E: Alemania, Reino Unido, Bélgica, Suiza, Noruega, Francia, Holanda, Dinamarca, Austria, Suecia y Finlandia; aunque también están apareciendo nuevos mercados en América (Canadá y EE.UU.) y en Asia (Japón y China).

\section{LA IMPORTANCIA DEL COOPERATIVISMO Y DE LA INICIATIVA PRIVADA EN EL DESARRO- LLO AGRARIO}

Hasta la década de los años sesenta la elaboración de los vinos se realizaba de una manera muy artesanal, y el número de bodegas era prácticamente incontable, ya que en la mayoría de las casas de los agricultores tenían pequeños conos para el almacenamiento. Se trataba de pequeños lagares donde los cosecheros pisaban su propia producción de uva. Sobre este modo de fabricar vino (PALAO, 1961) indica que:

"El medio mecánico eran los pies calzados por alborgas y dando pisadas y vueltas como un molino se machacaba la uva, poco a poco, lentamente escurriendo aquel mosto que sería un rico vino después de su fermentación; el prensado era también natural, a base de la fuerza humana, una prensa pequeña de usillo se apretaba y a través de las cocinetas de esparto escurría el mosto rojo, vivo, hasta dejar casi agotado de él al orujo".

Pasados los años el avance de las tecnologías también ha llegado al proceso productivo que ya está mecanizado. Las inversiones han sido cuantiosas, hecho que ha provocado el cierre de muchas bodegas. El proceso de absorción y monopolización de la producción se ha ceñido prácticamente a pocas bodegas en ambas ciudades. La adquisición y aplicación de Nuevas Tecnología han sido básicas para acrecentar la competitividad de las empresas vinícolas del altiplano en un mercado de vinos muy competitivo. En Yecla en 1968 existían sólo trece bodegas y en 1971 se habían reducido a siete (MORALES, 1975), desapareciendo algunas tan emblemáticas como: Viuda de Petronilo Puche Puche, Juan Palao Díaz, Luis González Gómez, Martín Palao Puche, Ramón Candela García, Blas Navarro Sánchez o Juan Santa Muñoz. En 2013, quedan once: 
Cuadro $n^{\circ}$ 2. Bodegas en Yecla

\begin{tabular}{|l|l|}
\hline La Purísima & Antonio Candela e Hijos \\
\hline Castaño & Enrique Trenor y Lamo de Espinosa \\
\hline Lázaro del Corso & Evine \\
\hline Viñavista & Viñedos de Murcia \\
\hline La casa de las Especias & José Jiménez Serrano \\
\hline Señorío de Barahona & \\
\hline
\end{tabular}

Fuente: Denominación de Origen Yecla (2013).

Para el caso de Jumilla el número de bodegas se eleva a un total de veintinueve:

Cuadro $n^{o}$ 3. Bodegas en Jumilla

\begin{tabular}{|l|l|}
\hline Bleda & Asensio Carcelén \\
\hline San Isidro & Fernández \\
\hline Silvano García & Fermín Gilar Guardiola \\
\hline Guardiola & Pedro Luis Martínez \\
\hline Olivares & Omblancas \\
\hline Carchelo & Casa Castillo \\
\hline 1890 & Huertas \\
\hline Casa de la Ermita & Luzón \\
\hline Delampa & Elena \\
\hline Salzillo & Hijos de Juan Gil \\
\hline Campanero & El Nido \\
\hline Arloren & Hacienda El Carche \\
\hline Barón del Solar & J.M. Martínez Verdú \\
\hline Quórum & Vivanza \\
\hline Lo Nuevo Spain & \\
\hline
\end{tabular}

Fuente: Denominación de Origen Jumilla (2013). 


\section{Del paisaje agrario al paisaje RuRAl. TRAnSFormaciones aCtuales}

El desarrollo de la globalización de la economía, y en general de la sociedad, está influyendo notablemente en la transformación del paisaje, tanto urbano como rural. De hecho fotografías aéreas, planos catastrales, fotografías y documentación aportan un fuente sólida de estudio y confirman la gran mutación sufrida por el espacio objeto de estudio en menos de tres décadas. Nuevos sistemas de regadío y construcción de infraestructuras para almacenar el agua, aplicación de maquinaria (nuevas tecnologías), mejora de la red de caminos e incluso la aparición de otros usos del suelo no relacionado con la agricultura o ganadería como son las nuevas funciones terciarias. La actividad agraria desarrollada por la globalización potencia la aparición de una agricultura tecnificada, adaptada a la competitividad comercial y por tanto al ajuste de calidad/ precio; y este hecho repercute en el paisaje de forma muy palpable: extensión de nuevos regadíos, aparición de maquinaria sofisticada, y diversificación de la mano de obra. Y un lado aporta personal cualificado en diversos aspectos: contabilidad, manejo de maquinaria, programadores informáticos para los regadíos, etc. Por otro mano de obra "barata", que ejerce las tareas de plantación y recogida de productos. En este aspecto, la inmigración está jugando un papel decisivo, y cuanto más se intensifica la crisis económica el empleo de esta mano de obra es más demandada.

También el paisaje está cambiando por la aparición de actividades terciarias que nada tienen que ver con la agricultura y ganadería, como son los alojamientos rurales o las segundas residencias, muy demandadas por la necesidad de los ciudadanos de "abandonar el espacio urbano", al menos los fines de semana.

El enoturismo no deja de ser una actividad económica, lo que conlleva un uso del suelo y por tanto una transformación del espacio agrícola y urbano de los lugares en los que se desarrolla. En el caso de la Región de Murcia, observamos importantes transformaciones que vendrían a sintetizarse en diversos aspectos.

\subsection{Instalaciones vitivinícolas}

La remodelación de bodegas o construcción de nueva planta supone un gran esfuerzo de adaptación de un uso exclusivamente a espacio de producción a espacio de ocio y recreación, por ejemplo en las bodegas se integra las dependencias dedicadas a molturación, fabricación, depósito y embalaje de vino con otros espacios como restaurante, tienda de objetos y venta de vinos. 


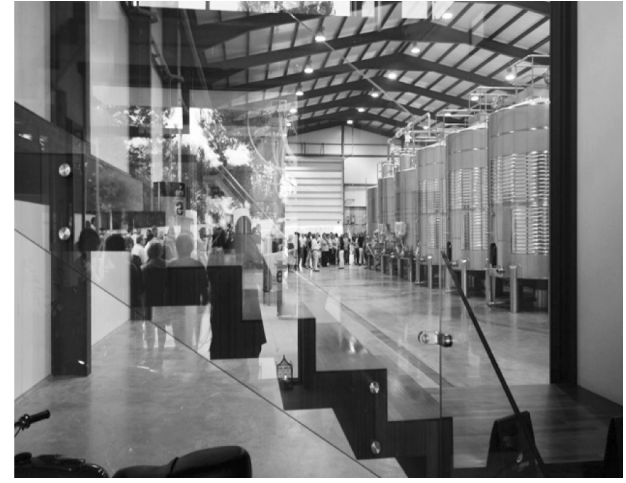

Imagen $n^{o} 1$ Bodegas Elena (Jumilla).

Fuente: www.vulka.es 2013.

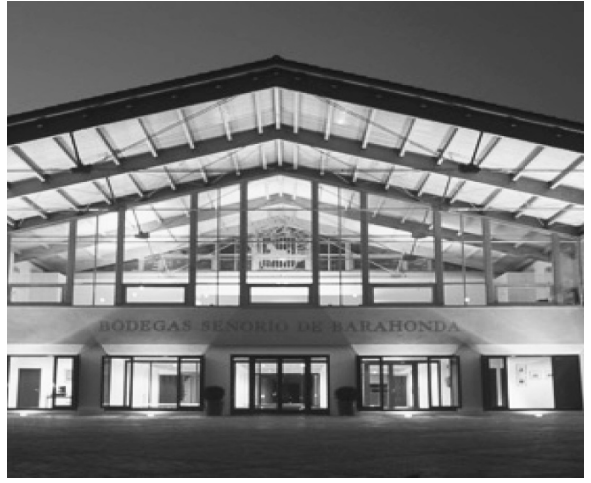

Imagen $n^{\circ} 2$ Bodegas Señorío de Barahona.

Fuente: www.vulka.es 2013.

\subsection{Señalización de las rutas}

La cartelería es siempre un buen reclamo para orientar y atraer a los clientes, aparece tanto en los lugares próximos a instalaciones vitivinícolas en medio del campo como en las propias ciudades de referencia, de hecho incluso los posibles restaurantes o bares de copas se pueden identificar con un distintivo que asegure su vinculación.

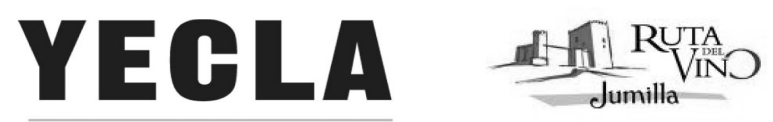

RUTA DEL vino

Figura $n^{\circ} 1$. Logos de las distintas rutas del vino y fiestas en Murcia

Fuente: http://www.rutadelvinoyecla.com/

\subsection{Creación de museos}

En la localidad de Jumilla, se anuncia la intención de crear un gran museo del vino en una superficie de $900 \mathrm{~m}^{2}$, que formaba parte de una antigua bodega y ahora se encuentra en estado de abandono, esta iniciativa museística representa una clara intencionalidad de fomentar la cultura del vino, de hecho en la ciudad existe un museo etnográfico y en varias bodegas privadas se muestran objetos y utensilios relacionados con la actividad vinícola.

\subsection{Sostenimiento de las tierras de cultivo y la dimensión ecológica}

El cultivo más importante en el espacio objeto de análisis es el viñedo, la producción de vino ha desarrollado la exportación de los caldos a diversas partes 
del mundo, de hecho en certámenes vinícolas no faltan los vinos del Altiplano murciano, esta circunstancia hace también que la producción vinícola generalmente consumida en territorio nacional haya acaparado mercados internacionales. El desarrollo rural trata de impulsar las actividades complementarias, como el turismo rural y la industria artesanal y asigna al campo la tarea de salvaguardar los recursos y el patrimonio natural, conservando y protegiendo el suelo fértil, los paisajes, los bosques y las riquezas ecológicas. De esta manera el mundo rural deja de ser un espacio exclusivamente agrario para convertirse en un espacio más diversificado, la globalización económica e incluso cultural contemporánea aparecen en el espacio agrario.

El cultivo del viñedo es poco consumidor de agua, lo cual refuerza la idea de adaptar las circunstancias climáticas y disponibilidades hídricas, siempre escasas, a unos cultivos sostenibles y poco agresivos con el medio ambiente; afortunadamente la viticultura en estas tierras reúne esas peculiaridades y salvo la capacidad de comercialización y competitividad de estos productos en todo lo referente a condiciones medioambientales el cultivo de la vid es un magnífico ejemplo en el pasado y futuro de estas tierras, un cultivo que se introdujo en época romana y permanece dos mil años después, demuestra su perfecta adaptabilidad al suelo y la actividad humana que ahora más que nunca aglutina la actividad tradicional productiva con una nueva dinámica terciaria, lo cual pone de relieve que las diferencias entre los modos de vida del campo y la ciudad están siendo borrados.

\subsection{Vinculación de la ruta del vino a la visita del patrimonio local.}

La visita a cada ruta del vino significa conocer y disfrutar el patrimonio local de la zona, de hecho se asocia a las diferentes rutas los principales museos, actos culturales o monumentos de interés histórico artístico que para el caso de Jumilla y Yecla son notables.

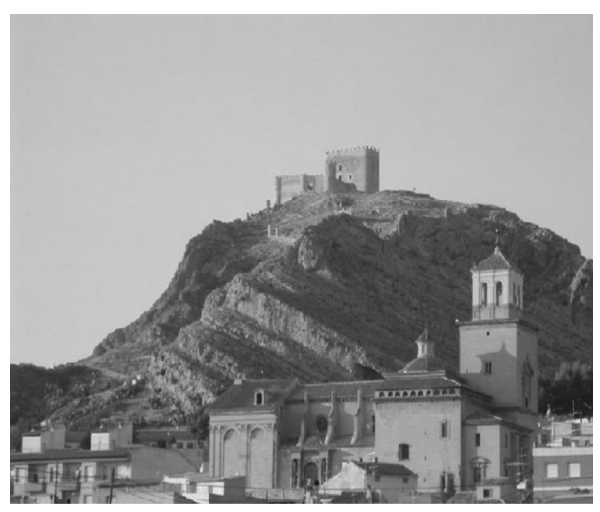

Imagen $n^{o}$ 3. Imagen de Junilla.

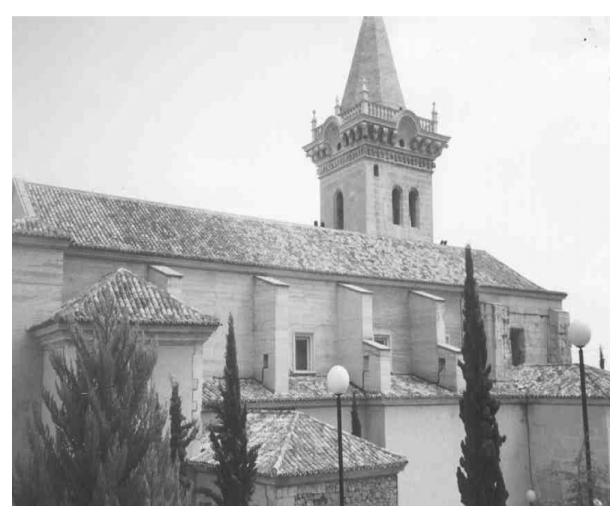

Imagen no 4. "Iglesia Vieja" de Yecla.

Fuente: F. Morales (2013).

Fuente: Ruta del vino de jumilla (2013). 


\subsection{Recursos hoteleros}

El sector hostelero de las denominaciones de origen estudiadas presentan grandes contrastes entre los lugares dedicados a las restauración y bares de vinos con la capacidad de alojamientos para pernoctar; abundan los primeros frente a una clara insuficiencia de los segundos, ello provoca la creación de un turismo de día, con un nivel de estancias muy corto, que no supera la media de 6 horas (Plan estratégico del turismo de Murcia). Los establecimientos hoteleros existentes tampoco son de gran nivel puesto que no existe ningún hotel de cuatro o cinco estrellas, sólo en Jumilla encontramos un establecimiento de tres estrellas.

Cuadro $n^{\circ}$ 2. Recursos hoteleros de las D.O. de Murcia (Año 2013)

\begin{tabular}{|l|c|c|}
\hline & D.O. Jumilla & D.O. Yecla \\
\hline $\mathrm{N}^{\text {o }}$ alojamientos hoteleros & 4 & 2 \\
\hline Alojamientos rurales & 4 & 3 \\
\hline $\mathrm{N}^{\text {o }}$ Plazas alojamientos total & 141 & 158 \\
\hline $\mathrm{N}^{\mathbf{o}}$ de Restaurantes & 13 & 18 \\
\hline Bodegas & 46 & 8 \\
\hline Bares de vinos & 11 & 14 \\
\hline Camping $\mathrm{n}^{\text {o }}$ plazas & 0 & 0 \\
\hline
\end{tabular}

Fuente: Plan Dinamización turística de Murcia (2007-2013).

De las bodegas existentes en las denominaciones en las distintas denominaciones de origen es importante destacar su localización por municipios:

Cuadro $n^{\circ}$ 3. Distribución de las bodegas por municipios y denominaciones de Origen

\begin{tabular}{|l|c|c|}
\hline \multicolumn{1}{|c|}{ Municipios } & D.O. Jumilla & D.O. Yecla \\
\hline Jumilla & 29 & \\
\hline Tobarra & 2 & \\
\hline Albatana & 2 & \\
\hline Fuenteálamo & 2 & \\
\hline Ontur & 3 & \\
\hline Montealegre del Castillo & 3 & \\
\hline Yecla & & 11 \\
\hline
\end{tabular}

Fuente: Consejos Reguladores de Denominación de Origen y elaboración Propia. 


\subsection{Patrimonialización de las fiestas dedicadas al Vino}

En las dos localidades objeto de estudios, se vincula de una forma muy significativa la celebración de fiestas con la exaltación del vino y las tareas agrarias, en el caso de Jumilla, en el mes de agosto coincide la feria, celebración de Moros y Cristianos y fiestas del vino, no cabe dudas que el conjunto de estos eventos genera para la localidad la visita de turistas y una proyección importante de la ciudad a nivel regional; la "cabalgata del vino" o la "fuente del vino" son espectáculos de gran atractivo turístico que atraen a miles de personas. También en una pedanía próxima Jumilla: "La Fuente del Pino", en el mes de octubre se recrean las denominadas: "Estampas rurales", en donde se presentan las tradicionales actividades del campo antes de la llegada del tractor y demás herramientas posteriores.

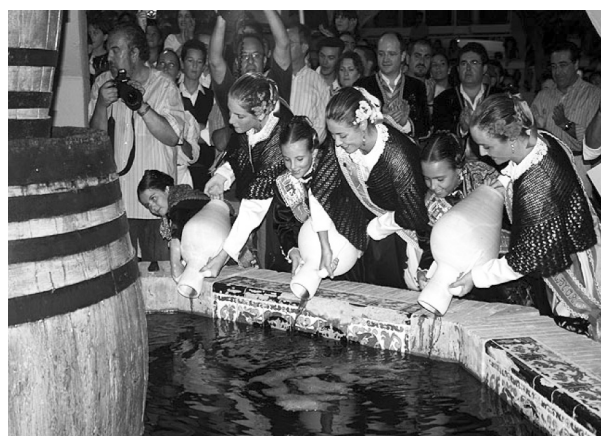

Imagen $n^{o}$ 5. Fuente del vino. Jumilla.

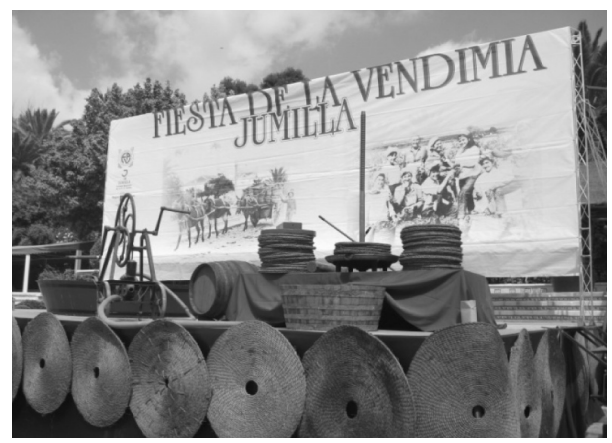

Imagen $n^{\circ}$ 6. Cabalgata del vino. Jumilla.

Fuente: web ayuntamiento de Jumilla (2012).

Fuente: web ayuntamiento de Jumilla (2012).

Finalmente en el municipio de Yecla, las fiestas dedicadas al vino se celebran en el mes de mayo coincidiendo con las denominadas "Fiestas de Primavera y San Isidro", destaca la cabalgata de carrozas engalanadas con motivos rurales y el concurso de catas de vino siempre asociado a la gastronomía local, la ciudad en esto días duplica la población, lo que genera un importante movimiento económico en el sector hostelero, al mismo tiempo los visitantes tienen la oportunidad de conocer el patrimonio histórico-artístico de la ciudad, destacando las visitas a museos y edificios singulares. 


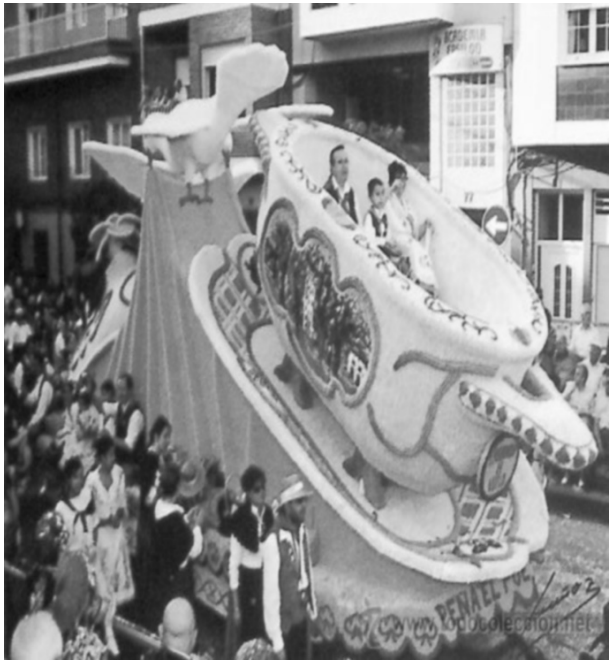

Imagen $n^{\circ}$ 7. Carrozas de papel. Yecla.

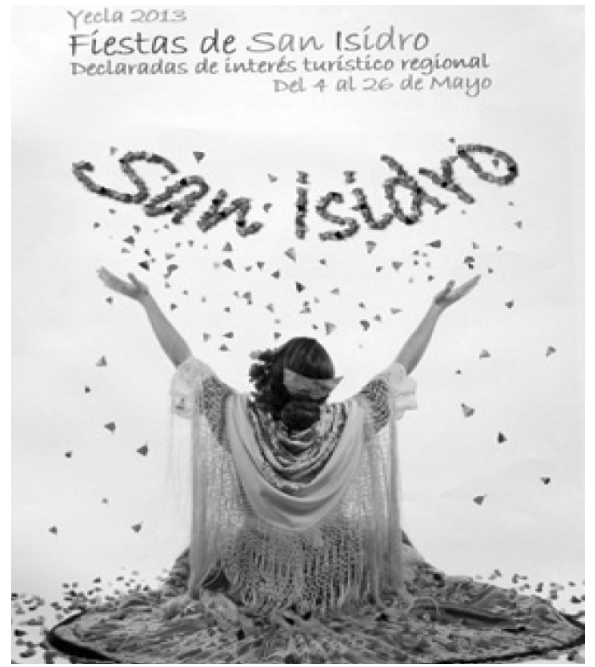

Imagen $n^{\circ}$ 8. Fiestas de San Isidro. Yecla.

Fuente: web ayuntamiento de Yecla (2012).

\section{Conclusiones}

Las conclusiones de este trabajo pretenden recoger los aspectos más relevantes de este trabajo y se reseñan a continuación:

1. El sector agrario siempre ha ocupado un papel muy importante en la economía local de las ciudades objeto de estudio, esencialmente en el municipio de Jumilla ha sido el principal motor de la economía local, en el caso de Yecla su rápida industrialización a partir de los años 60 en la industria del mueble relegó a la agricultura a un plano secundario. Las rutas del vino suponen un más que evidente incremento en la generación de rentas en un momento de crisis aguda en las economías industriales que están siendo incapaces de hacer frente a la expansión de los productos industriales procedentes de Oriente, generalmente de peor calidad pero mucho más económicos en cuanto a precios.

2. La potencialidad del turismo rural, liderada por el enoturismo (MONNIER, 2010) se perfila como un sector estratégico ya que está influyendo en aspectos como la visita a bodegas (ZÁRATE, 2010) y posterior venta de productos, mayores ingresos en el sector hostelero y visita a lugares de interés cultural (DUBOSCQ, 2010) que no han terminado de potenciarse en épocas anteriores.

3. Las tareas agrícolas y buenas prácticas en la tierra ofrecen la posibilidad de incrementar un mayor desarrollo sostenible y mejora en la protección 
del medio ambiente así como la preservación de especies de flora y fauna autóctonas.

4. Tecnificación, formación del personal e inversiones son elementos clave para afrontar la competencia de otros mercados emergentes que suponen un grave riesgo para la continuidad del sector agrario en estos municipios.

5. La expansión y puesta en valor del enoturismo supondrá la creación de nuevos yacimientos de empleo y la posibilidad de complementar rentas para algunos agricultores, el caso del alquiler de casas rurales está todavía por desarrollar con fuerza en estas comarca.

6. Las administraciones públicas a pesar de la actual situación económica de numerosos recortes presupuestarios deben racionalizar e incrementar las inversiones que potencien directamente cuestiones tan diversas como: mejora de infraestructuras y redes viarias, difusión y marketing de productos, negociación de acuerdos en la U.E., dinamización de planes de turismo interior o la negociación de acuerdos en la U.E., como por ejemplo el perjudicial tratado de la U.E. con Marruecos en febrero de 2012 que supone importantes problemas para los sectores hortofrutícolas de Andalucía, Murcia o Valencia por la competencia desleal en cuanto a los costes de mano de obra de los trabajadores o la falta de controles fitosanitarios en el país magrebí. Es imprescindible continuar e incrementar la colaboración entre empresas y ayuntamientos en el marco de las rutas del vino.

7. En el análisis realizado destaca como posibles áreas de mejora para dinamizar el sector la internacionalización de los vinos de estas zonas, así como la continuidad en el esfuerzo de ofrecer un producto de calidad certificado por los grandes sumillers.

8. Es preciso una mayor cohesión entre las dos denominaciones de origen para crear una única ruta del vino en la comarca, hasta el momento los puntos de encuentro y acercamiento entre los municiopios son poco relevantes, existen más recelos que colaboración y búsqueda de metas conjuntas.

9. El enoturismo es una gran oportunidad para diversificar la economía en estos espacios, de hecho la actividad comercial, hostelera y de restauración en general se puede ver beneficiada.

10. Por último y de manera muy destacada entre las conclusiones, se estima oportuno la potenciación y búsqueda de nuevos productos turísticos relacionados alrededor de la cultura del vino, los paisajes culturales, la gastronomía; para ello se requiere un esfuerzo de creatividad e inversiones económicas tanto por parte de capital público como privado. 


\section{BIBLIOGRAFÍA}

ALONSO, J.L. (2003): "Redes y procesos de innovación en las comarcas vinícolas de Castilla y León: el ejemplo de la D.O. Bierzo". Boletín de la Asociación de Geógrafos Españoles, No 36. Madrid. pp. 43-60.

ANDRÉS, J.L. (2000): “Aportaciones básicas del turismo al desarrollo rural”.

Cuadernos de Turismo, $\mathrm{N}^{\mathrm{0}}$ 6. pp. 45-59.

ASERO, V., PATTI, S. (2009): "From wine production to wine tourism experience. The case of Italy". American Asociation of Wine Economics. Consultada en www.wineeconomics.org el 11 de Febrero de 2013.

BLÁZQUEZ, J. (1987): Yecla en tiempos de Felipe II (1556-1598). Ed. Excmo. Ayuntamiento de Yecla. 137 págs.

CÁNOVES, G., HERRERA L., VILLARINO, M. (2005): “Turismo rural en España: paisajes, nuevos usos y nuevas visiones". Cuadernos de Turismo, $\mathrm{N}^{\mathrm{0}}$ 15. pp. 63-76.

CÁNOVES, G., HERRERA, L., BLANCO, A. (2005): “Turismo rural en España: un análisis de la evolución en el contexto europeo”. Cuadernos de Geografía, No 77 , pp. 41-58.

COLLADO, M y OTROS (2000): En el umbral del siglo XXI. Ed. Excmo. Ayuntamiento de Quintanar del Rey (Cuenca). 242 págs.

DUBOSCQ, M.CH. (2010): "La comercialización del enoturismo en Francia". Libro de actas del $2^{\circ}$ Congreso Europeo de Turismo industrial. Toledo 2008. pp. 186-191.

III FORUM de Turismo de Interior de la Comunidad Valenciana (2008). Capítulo 5. Iniciativas innovadoras en la gestión del turismo de interior. Ed. Observatorio de investigación local y geografía económica. Dpto. Geografía Humana. Universidad de Alicante. pp. 64-85.

III FORUM de Turismo de Interior de la Comunidad Valenciana (2008).Capítulo 8. Los planes de dinamización del producto turístico, como modelos de gestión y desarrollo. Ed. Observatorio de investigación local y geografía económica. Dpto. Geografía Humana. Universidad de Alicante. pp. 120147.

GOYET, P. (2010): "El turismo vitivinícola: el caso de Francia”. Libro de actas del $2^{\circ}$ Congreso Europeo de Turismo industrial. Toledo 2008. pp. 171-177 JIMÉNEZ, P (1865): Memoria de apuntes para la historia de Yecla.

LÓPEZ T, J., SÁNCHEZ, S.M. (2008): "La creación de productos turísticos utilizando rutas enológicas". Pasos. Revista de Turismo y Patrimonio Cultural, Vol. 6, No 2, pp. 159-171.

LÓPEZ, A (1997): Yecla: un ejemplo de socialismo agrario (1914-1918) Ed. Real Academia Alfonso X "El Sabio". Murcia. 235 págs.

MATELLANES, M. (2008): "Gestión del enoturismo en la D.O. Ribera del Duero de España”. Directores: Dr. Salvador Hernández Navarro y Dra. 
Adriana Corrêa Guimarâes. Tesis doctoral para optar al grado de Doctora por la Universidad de Valladolid. Universidad de Valladolid, 2008.

MONNIER, J.M. (2010): "La profesionalización del turismo vitivinícola: el ejemplo del Loira". Libro de actas del $2^{\circ}$ Congreso Europeo de Turismo industrial. Toledo 2008. pp. 179-185.

MORALES, A. (1975): El Altiplano de Jumilla-Yecla. Ed. Universidad de Murcia. 467 págs.

MORALES, F.J. (2005): Efectos de la globalización en la actividad económica de Yecla. Ed. Excmo. Ayuntamiento de Yecla. 228 págs.

MORALES, F.J. (2008): Agua y paisaje en Yecla. Ed. Excmo. Ayuntamiento de Yecla. 223 págs.

MORALES, F.J. (2012): "Redes y procesos de innovación turística en las comarcas vitivinícolas de la región de Murcia: las rutas del vino y sus consecuencias en la transformación del paisaje". Actas V congreso desarrollo Local. AGE. Sevilla.

SÁNCHEZ, J.L. (2003): "Capital exógeno y procesos de innovación en la industria vinícolas de la denominación de origen Toro". Boletín de la Asociación de Geógrafos Españoles. № 36. Madrid. pp. 61-80.

PALAO, C. (1961): "Análisis de Yecla como núcleo industrial". Anales de Filosofía y Letras de la Universidad de Murcia. pp. 67-73.

PARENTEAU, A. (2010): "Estado del turismo enológico en Europa". Libro de actas del $2^{\circ}$ Congreso Europeo de Turismo industrial. Toledo 2008, pp. 166-170.

PULIDO, J.I. Y OTROS (2011): "El turismo rural en España. Orientaciones estratégicas para una tipología aún en desarrollo". Boletín de la Asociación de Geógrafos Españoles. N ${ }^{\circ}$ 56. Madrid. pp. 155-176.

RICO, A. (2006): "Políticas agrarias, eficiencia socioeconómica y retos de futuro en los regadíos intensivos". Boletín de la Asociación de Geógrafos Españoles, $\mathrm{N}^{\circ}$ 41. Madrid. pp. 113-150.

SILVA, R. (2002): "Estrategias de inserción de las áreas rurales en la economía mundial. Una aproximación desde Andalucía" Boletín de la Asociación de Geógrafos Españoles, № 33. Madrid. pp. 103-134.

SORIANO, F. (1972): Historia de Yecla. Ed. Domenech. 297 págs.

VELASCO, M. (2009): "Gestión turística del patrimonio cultural: enfoques para un desarrollo sostenible del turismo cultural". Cuadernos de Turismo, $\mathrm{N}^{\circ}$ 23, pp. 237-235.

ZÁRATE, M.A. (2010): La "visita de empresa" en España, una modalidad turística en expansión. Libro de actas del $2^{\circ}$ Congreso Europeo de Turismo industrial. Toledo 2008. pp. 52-66. 